\title{
Sistema de avaliação de rendimento escolar do Estado de São Paulo: mapeamento e tendências temáticas da produção científica brasileira (1996-2011).
}

\author{
Rafael Gabriel de Oliveira Júnior* \\ Adolfo Ignacio Calderón**
}

\section{Resumo}

O presente artigo apresenta um mapeamento e análise das tendências temáticas da produção científica brasileira em torno do Sistema de Avaliação de Rendimento Escolar do Estado de São Paulo (SARESP), referente ao período de 1996 a 2011, sistematizando 42 estudos, entre teses de doutorado e dissertações de mestrado, a partir das seguintes categorias: área do conhecimento, linha do tempo da produção científica (cronologia), procedência institucional, distribuição regional, principais orientadores, eixos e tendências temáticas. Verificou-se uma disposição, por parte dos pesquisadores, em analisar os resultados dos alunos nas provas do SARESP, preocupações com os aspectos técnicos da constituição das avaliações e as produções dos alunos, especialmente nas áreas de Português e Matemática, bem como análises dos impactos desse formato avaliativo no contexto escolar. Constatou-se a predominância de uma comunidade epistêmica, hegemônica em termos teórico-discursivos, ancorada no paradigma do conflito. Palavras-chave: SARESP. Avaliação em larga escala. Avaliação Educacional. Educação Básica.

\section{Observação preliminar}

O presente artigo insere-se no campo dos estudos sobre o Estado da Arte, isto é, um campo que tem como norte compreender a evolução e as tendências do conhecimento científico produzido sobre determinada temática ou área do conhecimento

\footnotetext{
Mestre em Educação pela Pontifícia Universidade Católica de Campinas (PUC-Campinas). Membro do Grupo de Pesquisa "Gestão e Políticas Públicas em Educação" da PUC-Campinas. E-mail: rafaellgabriel@hotmail.com

** Pós-Doutorado em Ciências da Educação na Universidade de Coimbra. Docente-pesquisador do Programa de Mestrado em Educação da Pontifícia Universidade Católica de Campinas. E-mail: adolfo.ignacio@ puc-campinas.edu.br
} 
(FERREIRA, 2002; PUENTES, AQUINO, FAQUIM, 2005; CALDERÓN, FERREIRA, 2011). Nessa ótica, este artigo, busca identificar, acompanhar e avaliar as tendências da produção científica brasileira em torno do SARESP, principal sistema de avaliação da educação básica do Estado de São Paulo.

No que ser refere ao SARESP, convém registrar que se trata de uma avaliação de caráter censitário implantada em 1996, que abrange, obrigatoriamente, a participação de todas as escolas públicas estaduais do ensino regular. São avaliados alunos do $3^{\circ}, 5^{\circ}, 7^{\circ}$ e $9^{\circ}$ anos do ensino fundamental, e do $3^{\circ}$ ano do ensino médio. Para monitorar a qualidade do ensino paulista e subsidiar as políticas públicas educacionais, essa avaliação aplica provas cognitivas e questionários para alunos, professores, pais e gestores de ensino (SÃO PAULO, 2012).

Está em questão uma política educacional que, em sua vigência, passou por uma série de estratégias de aprimoramento, rupturas, resistências, impactando nas unidades escolares e contribuindo para a instauração da cultura da avaliação nas políticas educacionais paulistas, em consonância com as tendências da avaliação na educação brasileira, especialmente a partir da década de 1990, no contexto da reforma do Estado.

Ao longo de seu processo de implantação e funcionamento, o SARESP despertou interesse de muitos pesquisadores ligados a importantes universidades e centros de investigação, resultando em pesquisas de grande relevância para a compreensão desse sistema de avaliação, disseminadas principalmente por meio de pesquisas em nível de mestrado e doutorado e artigos científicos. Convém registrar que estudos realizados, na década de 1990, sobre o Estado da Arte na área da educação (CANDAU; OSWALD, 1995; SOARES, 1991), já apontavam que tanto artigos publicados em periódicos científicos como dissertações de mestrado e teses de doutorado, constituem os principais meios de expressão do conhecimento científico em construção. Nessa ótica, a disseminação de conhecimentos por meio de livros acaba sendo secundarizada, já que sua divulgação depende da aprovação de editoras, muitas das quais, mesmo sendo editoras universitárias, diferentemente das teses, dissertações e artigos publicados em periódicos científicos, não passam por critérios de validade teórica ou mérito científico dos livros publicados.

Nesse contexto, este artigo tem por objetivo apresentar à comunidade científica um mapeamento da produção científica brasileira em torno do Sistema de Avaliação 
de Rendimento Escolar do Estado de São Paulo (SARESP), tendo como foco de análise as teses de doutorado e dissertações de mestrado defendidas no Brasil sobre o assunto, no período de 1996 a 2011, priorizando o caráter diagnóstico e inventariante próprio das pesquisas sobre o Estado da Arte, as quais:

Definidas como de caráter bibliográfico, elas parecem trazer em comum o desafio de mapear e de discutir uma certa produção acadêmica em diferentes campos do conhecimento, tentando responder que aspectos e dimensões vêm sendo destacados e privilegiados em diferentes épocas e lugares, de que formas e em que condições têm sido produzidas certas dissertações de mestrado, teses de doutorado, publicações em periódicos e comunicações em anais de congressos e de seminários. Também são reconhecidas por realizarem uma metodologia de caráter inventariante $\mathrm{e}$ descritivo da produção acadêmica e científica sobre o tema que busca investigar, à luz de categorias e facetas que se caracterizam enquanto tais em cada trabalho e no conjunto deles, sob os quais o fenômeno passa a ser analisado (FERREIRA, 2002, p. 258).

Optamos por estudar as dissertações e teses devido ao volume reduzido de artigos científicos disseminados nas revistas consideradas de alto impacto, por exemplo, uma busca na Scientific Electronic Library Online (SciELO), com o termo Saresp, na forma de sigla ou escrita por extenso, permitiu localizar um único artigo, o texto de Bauer (2011). Também, em busca realizada no portal Educ@- Periódicos online de Educação da Fundação Carlos Chagas, localizou-se apenas seis artigos, três deles de Bauer (2011, 2010, 2008), e outros assinados por Serpa e Pontes (2013), Natis (2001) e Andrade (2001). Além dos artigos mencionados, convém registrar que não foram captados, nas buscas realizadas nos portais em questão, dois artigos cujas edições, em que foram publicados, não estão disponíveis online, mas que abordam diretamente a questão da operacionalização do Saresp. Trata-se dos artigos de Esposito, Davis e Nunes (2000), e Arcas (2010).

Para a definição das teses e dissertações consideradas neste estudo, realizamos buscas em espaços digitais da CAPES, especificamente no seu Banco de Teses, e também no site do Ministério da Ciência e Tecnologia, por meio da Biblioteca Digital de Teses e Dissertações do Instituto Brasileiro de Informação em Ciência e Tecnologia (BDTD), que resultaram em 382 teses e dissertações relacionadas ao SARESP. O número elevado de trabalhos localizados é resultado 
de levantamento realizado por meio dos termos "SARESP" e "Sistema de Avaliação do Rendimento Escolar do Estado de São Paulo", inicialmente de forma isolada e depois combinando as duas expressões.

Dessa forma, abrimos um processo de depuração e triagem dos trabalhos que serviram como base referencial da pesquisa, a partir da leitura dos resumos, objetivando selecionar os estudos com abordagem sobre o SARESP de forma mais específica. Excluindo os trabalhos que apenas tangenciavam o assunto, chegamos ao número de 42 teses e dissertações consideradas relevantes para o mapeamento.

Assim, a partir de leituras de resumos, introduções, conclusões, bem como da leitura integral de alguns trabalhos sobre o SARESP, voltamo-nos a responder questões levantadas para o estudo, tais como: quantas e quais são as teses e dissertações produzidas sobre o SARESP? Quais são os orientadores dos trabalhos e seus vínculos institucionais? Quais instituições produziram teses e dissertações sobre o SARESP? Como estão distribuídas as pesquisas, considerando os diversos momentos históricos do SARESP? Quais os anos com maior produção acerca do SARESP? Quais os eixos temáticos e as tendências temáticas predominantes nos estudos focados no SARESP?

Considerando as limitações muitas vezes existentes no trabalho bibliográfico com análise de resumos, já alertadas por Calderón e Ferreira (2011), tais como imprecisão das informações e caráter abrangente e genérico dos conteúdos, procedemos à localização e análise da introdução, conclusão e, quando necessário, leitura integral dos trabalhos selecionados; encontrando-se algumas dificuldades, uma vez que muitas dessas pesquisas não estão disponíveis online, e até na própria instituição de origem.

O recorte temporal de 1996 a 2011 considerou o ano de criação do sistema de avaliação como início da presente investigação, sendo que o primeiro estudo foi localizado dois anos depois, em 1998. Trata-se da dissertação de mestrado Uma avaliação política do projeto SARESP, de Oliveira (1998), defendida em 10 de março de 1998, na Universidade Estadual de Campinas (UNICAMP), sob a orientação da Professora Dra. Lúcia Avelar. Apesar da curta distância existente - quase dois anos entre a implantação do SARESP, em 23 de abril de 1996, até a produção do primeiro estudo, no âmbito dos Programas de Pós-Graduação Stricto Sensu, o trabalho de Oliveira (1998) conseguiu tecer as primeiras análises sobre os resultados do SARESP, tomando como referencia as duas primeiras edições: a de 1996 e a de 1997. 


\section{Os estudos referentes ao SARESP}

Entre os estudos sobre o SARESP, conforme a Tabela 1, observamos predominância absoluta das dissertações de mestrado ${ }^{1}$, quando comparadas com o número de teses de doutorado ${ }^{2}$.

Encontramos, também, dissertações de mestrado profissional, ${ }^{3}$ que aparecem com $9,5 \%$ dos trabalhos. Se considerarmos que o primeiro estudo nessa modalidade acerca do SARESP, nos critérios de nossa pesquisa, ocorreu em 2007, cujo autor é Júlio César da Silva (2007), o número de quatro trabalhos coloca-se como significativo, por ser uma modalidade de pesquisa em nível de pós-graduação stricto senso de recente implantação no Brasil.

Tabela 1 - Distribuição dos números de dissertações de mestrado, mestrado profissional e teses de doutorado sobre o SARESP de 1996 a 2011

\begin{tabular}{|l|c|c|}
\hline Classificação & Número de pesquisas & $\%$ \\
\hline Mestrado acadêmico & 35 & 83,4 \\
\hline Mestrado profissionalizante & 4 & 9,5 \\
\hline Tese doutorado & 3 & 7,1 \\
\hline Total & 42 & 100 \\
\hline
\end{tabular}

Fonte: Os autores (2014).

As produções em nível de mestrado profissional são resultado do Programa mestrado \& doutorado do Governo do Estado de São Paulo (SÃO PAULO, 2012a), iniciado em 2004, com o objetivo de qualificar, atualizar e aperfeiçoar os profissionais da rede paulista.

Dessas pesquisas, três autores estão vinculados à Pontifícia Universidade Católica de São Paulo (PUC-SP): Silva (2007), Vaz (2008) e Chiste (2009); já Lugli (2011) tem vínculo com a Universidade Cruzeiro do Sul (UNICSUL). Todos os trabalhos abordam questões relativas à área de Matemática do SARESP.

1 Autores: Oliveira (1998); Esteves (1998); Felipe (1999); Valle (1999); Kawauchi (2001); Ribeiro (2001); Bosquetti (2002); Gutierre (2003); Túbero (2003); Hernandes (2003); Mesko (2004); Barbosa (2005); Teixeira (2005); Ceneviva (2006); Prudêncio (2006); Baggio (2006); Silva (2006); Augusto (2006); Bauer (2006); Souza (2007); Dorta (2007); Sazdjian (2007); Maruci (2007); Ferreira (2007); Ribeiro (2008); Freire (2008); Maldonado (2008); Corrêa (2008); Rahal (2010); Alcântara (2010); Girelli (2010); Alves (2011); Clemente (2011); Pinto (2011); Rodrigues (2011).

2 Autores: Machado (2003); Arcas (2009); Camba (2011).

3 Autores: Silva (2007); Vaz (2008); Chiste (2009); Lugli (2011). 
Conforme a Tabela 2, desde 1998 - ano do primeiro trabalho sobre o SARESP (OLIVEIRA, 1998) - a média é de pelo menos três por ano. O ano de 2000 é o único que não apresenta produção científica de mestrado e doutorado. Além disso, o período com maior incidência de pesquisas se dá entre 2006 e 2008, com queda entre 2009 e 2010 e retomada de crescimento significativo do número de trabalhos em 2011.

Tabela 2 - Distribuição da produção, por ano de defesa, das dissertações de mestrado e teses de doutorado de 1996 a 2011

\begin{tabular}{|l|c|c|}
\hline Ano de defesa & Quantidade & \% \\
\hline 1996 & - & - \\
\hline 1997 & - & 4,8 \\
\hline 1998 & 2 & 4,8 \\
\hline 1999 & 2 & - \\
\hline 2000 & - & 4,8 \\
\hline 2001 & 2 & 2,4 \\
\hline 2002 & 1 & 9,5 \\
\hline 2003 & 4 & 2,4 \\
\hline 2004 & 1 & 4,8 \\
\hline 2005 & 2 & 14,2 \\
\hline 2006 & 6 & 14,2 \\
\hline 2007 & 6 & 11,9 \\
\hline 2008 & 5 & 4,8 \\
\hline 2009 & 2 & 7,1 \\
\hline 2010 & 3 & 14,3 \\
\hline 2011 & 6 & 100 \\
\hline Total & 42 & \\
\hline
\end{tabular}

Fonte: Os autores (2014).

\section{Os centros de produção do conhecimento}

As instituições envolvidas na produção das teses de doutorado e dissertações de mestrado sobre o SARESP somam 14, conforme a Tabela 3. A PUC-SP aparece com o maior número de produções, um total de 13, seguida pela UNESP e pela Universidade de São Paulo (USP), com oito e sete, respectivamente. A UNICAMP $^{4}$ apresenta quatro trabalhos. O grande número de produções da 4 Oliveira (1998); Mesko (2004); Ribeiro (2008); Camba (2011). 
$\mathrm{PUC} \mathrm{SP}^{5}, \mathrm{UNESP}^{6}$ e $\mathrm{USP}^{7}$ pode ser explicado pelas diversas linhas de pesquisa existentes nessas instituições e pela amplidão que o próprio assunto SARESP possibilita em termos de áreas de conhecimento afins.

Tabela 3 - Distribuição das instituições envolvidas nas produções acerca do SARESP

\begin{tabular}{|l|c|c|}
\hline Instituições & $\begin{array}{c}\text { Quantidade } \\
\text { de trabalhos }\end{array}$ & $\%$ \\
\hline PUC-SP & 13 & 30,9 \\
\hline UNESP & 8 & 19 \\
\hline USP & 7 & 16,6 \\
\hline UNICAMP & 4 & 9,5 \\
\hline Universidade Federal de São Carlos (UFSCAR) & 1 & 2,4 \\
\hline Fundação Getúlio Vargas (FGV) & 1 & 2,4 \\
\hline Universidade de Taubaté & 1 & 2,4 \\
\hline Universidade São Francisco & 1 & 2,4 \\
\hline Universidade de Sorocaba & 1 & 2,4 \\
\hline Universidade Cidade de São Paulo & 1 & 2,4 \\
\hline Universidade Metodista de São Paulo & 1 & 2,4 \\
\hline Universidade Federal de São Paulo (UNIFESP) & 1 & 2,4 \\
\hline Centro Universitário Moura Lacerda & 1 & 2,4 \\
\hline Universidade Cruzeiro do Sul & 1 & 2,4 \\
\hline Total & 42 & 100 \\
\hline
\end{tabular}

Fonte: Os autores (2014).

Os trabalhos restantes somam 10 estudos, cada qual produzido por uma das seguintes instituições: Universidade Federal de São Carlos (UFSCAR), Fundação Getúlio Vargas (FGV) ${ }^{9}$, Universidade de Taubaté (UNITAU) ${ }^{10}$, Universidade São Francisco (USF) ${ }^{11}$, Universidade de Sorocaba (UNISO) ${ }^{12}$,

5 Esteves (1998); Felipe (1999); Ribeiro (2001); Bosquetti (2002); Barbosa (2005); Augusto (2006); Souza (2007); Sazdjian (2007); Silva (2007); Vaz (2008); Chiste (2009); Alcântara (2010); Rodrigues (2011).

6 Gutierre (2003); Hernandes (2003); Teixeira (2005); Silva (2006); Ferreira (2007); Maldonado (2008); Corrêa (2008); Pinto (2011).

7 Valle (1999); Kawauchi (2001); Machado (2003); Prudêncio (2006); Bauer (2006); Freire (2008); Arcas (2009).

8 Túbero (2003).

9 Ceneviva (2006).

10 Baggio (2006).

11 Dorta (2007).

12 Maruci (2007). 
Universidade Cidade de São Paulo (UNICID) ${ }^{13}$, Universidade Metodista de São Paulo (UMESP) ${ }^{14}$, Universidade Federal de São Paulo (UNIFESP) ${ }^{15}$, Centro Universitário Moura Lacerda (CUML) ${ }^{16}$ e UNICSUL ${ }^{17}$.

Conforme a Tabela 4, entre as 14 instituições envolvidas nas produções acerca do SARESP, observamos que cinco se enquadram na subcategoria de instituições "públicas (civis)": UNESP, UNICAMP, UFSCAR, USP e UNIFESP, uma vez que são mantidas por alguma esfera do Poder Público. A UNITAU apresenta algumas diferenças em relação às instituições citadas acima, por isso, está qualificada como "pública (autarquia municipal regime especial)". A manutenção dessa instituição é feita por meio das mensalidades pagas pelos alunos, sem o recebimento de subsídios diretos do governo municipal. Encontramos, ainda, instituições que se enquadram na subcategoria "privadas sem fins lucrativos - confessionais": são os casos da PUC-SP, USF e UMESP. Definidas como "privadas sem fins lucrativos" estão a FGV, CUML e UNICSUL. Na subcategoria "privadas sem fins lucrativos comunitárias", enquadra-se a UNISO. A única instituição "privada com fins lucrativos (sentido estrito)" é a UNICID.

Tabela 4 - Distribuição das instituições quanto ao formato de administração

\begin{tabular}{|l|c|c|c|}
\hline $\begin{array}{l}\text { Tipo institucional quanto ao } \\
\text { formato de administração }\end{array}$ & Instituições & $\begin{array}{c}\text { Quantidade } \\
\text { de trabalhos }\end{array}$ & $\%$ \\
\hline Públicas (civis) & $\begin{array}{c}\text { UNESP,UNICAMP, UFSCAR,USP, } \\
\text { UNIFESP }\end{array}$ & 21 & 50,0 \\
\hline $\begin{array}{l}\text { Pública (autarquia munici- } \\
\text { pal - regime especial) }\end{array}$ & UNITAU & 1 & 2,4 \\
\hline $\begin{array}{l}\text { Privadas sem fins lucrativos } \\
\text { (confessionais) }\end{array}$ & PUC-SP, USF, UMESP & 15 & 35,7 \\
\hline Privadas sem fins lucrativos & FGV, CUML, UNICSUL & 3 & 7,1 \\
\hline $\begin{array}{l}\text { Privadas sem fins lucrativos } \\
\text { (comunitárias) }\end{array}$ & UNISO & 1 & 2,4 \\
\hline $\begin{array}{l}\text { Privadas com fins lucrativos } \\
\text { (sentido estrito) }\end{array}$ & UNICID & 1 & 2,4 \\
\hline
\end{tabular}

Fonte: Os autores (2014).

13 Rahal (2010).

14 Girelli (2010).

15 Alves (2011).

16 Clemente (2011).

17 Lugli (2011). 
Em relação às áreas de conhecimento, a Tabela 5 apresenta três desdobramentos acerca do SARESP: Ciências Humanas, com maior predominância em número de trabalhos, seguida pelas Ciências Exatas, com sete trabalhos e Ciências Econômicas e da Administração, com apenas um trabalho relacionado ao SARESP.

Tabela 5 - Distribuição quanto à área de conhecimento

\begin{tabular}{|l|c|c|}
\hline Área do conhecimento & Quantidade & $\%$ \\
\hline Ciências Humanas & 34 & 80,9 \\
\hline Ciências Exatas & 7 & 16,7 \\
\hline Ciências Econômicas e da Administração & 1 & 2,4 \\
\hline Total & 42 & 100 \\
\hline
\end{tabular}

Fonte: Os autores (2014).

Os agrupamentos relacionados às áreas de conhecimento, conforme a Tabela 6, apresentam diversidade considerável no que toca às Ciências Humanas. As áreas de concentração "Educação" e "Linguística e Língua" somam 28 trabalhos, ou seja, aproximadamente $66 \%$ das pesquisas relacionadas ao SARESP. Já a área de "Matemática", que converge com as Ciências Exatas, apresenta um total de sete pesquisas.

\section{Tabela 6 - Distribuição quanto à área de concentração}

\begin{tabular}{|l|c|c|}
\hline Área de concentração & Quantidade & $\%$ \\
\hline Ciências Humanas & & \\
\hline Educação & 17 & 40,4 \\
\hline Linguística e Língua & 11 & 26,1 \\
\hline Currículo & 2 & 4,8 \\
\hline Serviço Social & 1 & 2,4 \\
\hline Psicologia & 2 & 4,8 \\
\hline História, Política e Sociedade & 1 & 2,4 \\
\hline Ciências Econômicas e Administrativas & 1 & \\
\hline Administração Pública e Governo & & 2,4 \\
\hline Ciências Exatas & 7 & 16,7 \\
\hline Matemática & 42 & 100 \\
\hline Total & & \\
\hline
\end{tabular}

Fonte: Os autores (2014). 
A Tabela 7 mostra que grande parte das pesquisas (aproximadamente $55 \%$ ) foi financiada por instituições, em nível federal e estadual paulista. A CAPES é a instituição com maior número de financiamentos: dez no total. Constam também, como agências financiadoras, o Conselho Nacional de Desenvolvimento Científico e Tecnológico (CNPq), com três financiamentos, e a Fundação de Amparo à Pesquisa do Estado de São Paulo (FAPESP), e o Fundo de Desenvolvimento da Educação em São Paulo (FUNDESP), com um financiamento cada. A Secretaria de Educação do Estado de São Paulo (SEESP) financiou oito pesquisas sobre o SARESP. Dois trabalhos aparecem com fomento da UNESP: Gutierre (2003) e Hernandes (2003); no entanto, mesmo em contato direto com a instituição, via telefone, não conseguimos obter informações acerca do formato desse financiamento. Os trabalhos sem discriminação de agência ou sem agência financiadora somam 17 , aproximadamente, $40,5 \%$ do total.

Tabela 7 - Distribuição das agências financiadoras de pesquisas acerca do SARESP

\begin{tabular}{|l|c|c|}
\hline Instituições & Quantidade & $\%$ \\
\hline CNPq & 3 & 7,1 \\
\hline CAPES & 10 & 23,8 \\
\hline FAPESP & 1 & 2,4 \\
\hline FUNDESP & 1 & 2,4 \\
\hline SEESP & 8 & 19 \\
\hline UNESP & 2 & 4,8 \\
\hline Sem agência financiadora & 17 & 40,5 \\
\hline Total & 42 & 100 \\
\hline
\end{tabular}

Fonte: Os autores (2014).

Entre os pesquisadores que orientam estudos sobre as questões do SARESP, conforme a Tabela 8, destacamos a docente Sandra M. Z. Lian Sousa, responsável pelo maior número de orientações (MACHADO, 2003; BAUER, 2006; FREIRE, 2008; ARCAS, 2009), defendidas na USP. Essa pesquisadora apresenta, em seu currículo, produção profusa e de grande relevância sobre avaliação educacional sendo, inclusive, muito referenciada por pesquisadores nessa área; assim, podemos afirmar a existência de aderência, em termos de estudo sobre avaliação, entre as pesquisas realizadas pela orientadora e os estudos de seus orientados. Essa aderência 
também é constatada em Sumiko Nishitani Ikeda, que apresenta duas orientações sobre o SARESP, na PUC-SP, em relação às questões de linguagem, bem como em Isabel Franchi Cappelletti, também com duas orientações relacionadas a currículo e avaliação educacional, defendidas na mesma universidade.

\section{Tabela 8 - Distribuição dos orientadores de trabalhos acerca do SARESP}

\begin{tabular}{|c|c|c|c|}
\hline Orientador dos trabalhos & Instituição & $\begin{array}{l}\text { Número } \\
\text { de orien- } \\
\text { tações }\end{array}$ & Autores dos trabalhos \\
\hline Sandra M. Zakia Lian Sousa & USP & 4 & $\begin{array}{l}\text { Cristiane Machado, Adriana } \\
\text { Bauer, Lilian Rose da Silva } \\
\text { Carvalho Freire, Paulo Henri- } \\
\text { que Arcas }\end{array}$ \\
\hline Isabel Franchi Cappelletti & PUC-SP & 2 & $\begin{array}{l}\text { Jesse Pereira Felipe, Rodrigo } \\
\text { Ferreira Rodrigues }\end{array}$ \\
\hline Sumiko Nishitani Ikeda & PUC-SP & 2 & $\begin{array}{l}\text { Fabiana de Fátima Augusto, } \\
\text { Anaid Bertezlian Sazdjian }\end{array}$ \\
\hline Amarílio Ferreira Júnior & UFSCAR & 1 & Rosana Túbero \\
\hline Ana Lúcia Manrique & PUC-SP & 1 & Monica Cristina Chiste \\
\hline Ana Maria da C. S. Menin & UNESP & 1 & Roseli Helena Ferreira \\
\hline Anna Maria Marques Cintra & PUC-SP & 1 & Iranéia Loiola de Souza \\
\hline Bárbara Lutaif Bianchini & PUC-SP & 1 & $\begin{array}{l}\text { Rosana Aparecida da Costa } \\
\text { Vaz }\end{array}$ \\
\hline Célia Maria David & UNESP & 1 & Soraya Rahal \\
\hline Célia Maria Haas & UNICID & 1 & $\begin{array}{l}\text { Márcio Alexandre Ravagnani } \\
\text { Pinto }\end{array}$ \\
\hline $\begin{array}{l}\text { Celi Aparecida Espasandin } \\
\text { Lopes }\end{array}$ & UNICSUL & 1 & Luciana de Castro Lugli \\
\hline Cileda de Q. e Silva Coutinho & PUC-SP & 1 & Júlio Cesar da Silva \\
\hline Dagoberto Buim Arena & UNESP & 1 & $\begin{array}{l}\text { Elianeth Dias Kanthack Her- } \\
\text { nandes }\end{array}$ \\
\hline Dalton Francisco de Andrade & USP & 1 & Raquel da Cunha Valle \\
\hline $\begin{array}{l}\text { Décio Azevedo Marques de } \\
\text { Saes }\end{array}$ & UMESP & 1 & Heitor Girelli \\
\hline Elzira Yoko Uyeno & UNITAU & 1 & Silvia Cristina Rossito Baggio \\
\hline Enid Abreu Dobranszky & USF & 1 & Roseli Aparecida Franco Dorta \\
\hline Fernanda Coelho Liberali & PUC-SP & 1 & Geraldo Carlos Barbosa \\
\hline
\end{tabular}




\begin{tabular}{|c|c|c|c|}
\hline Fernando Cesar Capovilla & USP & 1 & Erica Relvas Prudencio \\
\hline Helena M. de P. Albuquerque & PUC-SP & 1 & Helena Sant Anna Alcantara \\
\hline José Luis Sanfelice & UNICAMP & 1 & Denise da Silva Ribeiro \\
\hline Lúcia Mercês de Avelar & UNICAMP & 1 & $\begin{array}{l}\text { Duzolina Alfredo Felipe de } \\
\text { Oliveira }\end{array}$ \\
\hline Luis Enrique Aguilar & UNICAMP & 1 & Mariangela Camba \\
\hline Luiz Carlos de Freitas & UNICAMP & 1 & Wladimir Stempniak Mesko \\
\hline Luiz Percival Leme Britto & UNISO & 1 & $\begin{array}{l}\text { Fátima Aparecida de Souza } \\
\text { Maruci }\end{array}$ \\
\hline Maria L. P. Barbosa Franco & PUC-SP & 1 & $\begin{array}{l}\text { Maria Eunice de Paiva Pinto e } \\
\text { Esteves }\end{array}$ \\
\hline $\begin{array}{l}\text { Maria Raquel Miotto Mo- } \\
\text { relatti }\end{array}$ & UNESP & 1 & Laura Maria Corrêa \\
\hline Marize M. D. Hattinher & UNESP & 1 & Maria Luiza de Sousa Teixeira \\
\hline Marta Ferreira Santos Farah & FGV & 1 & Ricardo Ceneviva \\
\hline $\begin{array}{l}\text { Natalina Aparecida Laguna } \\
\text { Sicca }\end{array}$ & CUML & 1 & Cesar Clemente \\
\hline Nelson Piletti & USP & 1 & Mary Kawauchi \\
\hline Renata Junqueira de Souza & UNESP & 1 & Rosângela Garcia Maldonado \\
\hline Renata M. F. C. Marchezan & UNESP & 1 & $\begin{array}{l}\text { Maria Madalena Borges } \\
\text { Gutierre }\end{array}$ \\
\hline Ricardo Ribeiro & UNESP & 1 & $\begin{array}{l}\text { Hilda Maria Gonçalves da } \\
\text { Silva }\end{array}$ \\
\hline Rosário Silvana Genta Lugli & UNIFESP & 1 & Caio Augusto Carvalho Alves \\
\hline Silvia Dias A. Machado & PUC-SP & 1 & $\begin{array}{l}\text { Maria Carolina Bonna Bos- } \\
\text { quetti }\end{array}$ \\
\hline Tânia M. Mendonça Campos & PUC-SP & 1 & Alessandro Jacques Ribeiro \\
\hline Total & & 42 & \\
\hline
\end{tabular}

Fonte: Os autores (2014).

\section{Autores, tendências e eixos temáticos}

As pesquisas referentes ao SARESP, no período de 1996 a 2011, apresentam interesse em edições ocorridas até o ano de 2009, conforme a Tabela 9. A edição mais pesquisada é a de 2005, com empenho de 11 pesquisadores. Esse número elevado converge com o maior número de produções referentes aos anos de 2006, 2007 e 2008, conforme identificado na Tabela 2. 


\section{Tabela 9 - Distribuição relacionada aos interesses por edições do SARESP}

\begin{tabular}{|c|c|c|}
\hline $\begin{array}{l}\text { Ano da } \\
\text { edição }\end{array}$ & Número & Autores \\
\hline 1996 & 4 & Oliveira (1998); Esteves (1998); Valle (1999); Silva (2006) \\
\hline 1997 & 7 & $\begin{array}{l}\text { Oliveira (1998); Esteves (1998); Valle (1999); Ribeiro (2001); Silva } \\
\text { (2006); Ferreira (2007); Girelli (2010) }\end{array}$ \\
\hline 1998 & 3 & Felipe (1999); Esteves (1998); Silva (2006) \\
\hline 2000 & 6 & $\begin{array}{l}\text { Túbero (2003); Machado (2003); Bosquetti (2002); Barbosa (2005); } \\
\text { Silva (2006); Girelli (2010) }\end{array}$ \\
\hline 2001 & 4 & Hernandes (2003); Ribeiro (2001); Teixeira (2005); Silva (2006) \\
\hline 2002 & 3 & Prudêncio (2006); Silva (2006); Ferreira (2007) \\
\hline 2003 & 5 & $\begin{array}{l}\text { Baggio (2006); Barbosa (2005); Silva (2006); Souza (2007); Maldona- } \\
\text { do (2008) }\end{array}$ \\
\hline 2004 & 4 & Silva (2006); Souza (2007); Maldonado (2008); Clemente (2011) \\
\hline 2005 & 11 & $\begin{array}{l}\text { Ferreira (2007); Sazdjian (2007); Vaz (2008); Barbosa (2005); Freire } \\
\text { (2008); Dorta (2007); Silva (2006); Maldonado (2008); Corrêa (2008); } \\
\text { Girelli (2010); Clemente (2011) }\end{array}$ \\
\hline 2007 & 4 & Chiste (2009); Girelli (2010); Alves (2011); Lugli (2011) \\
\hline 2008 & 3 & Alves (2011); Clemente (2011); Lugli (2011) \\
\hline 2009 & 1 & Lugli (2011) \\
\hline
\end{tabular}

Fonte: Os autores (2014).

Em relação aos interesses identificáveis dos autores pelos níveis de ensino, o ensino fundamental tem preferência em grande medida, conforme a Tabela 10. A diferença de preferência entre o ensino fundamental e o ensino médio pode ser explicada, de certa maneira, pelos anos em que o ensino médio foi avaliado, e até por uma questão de intermitência em relação às avaliações do ensino fundamental. $\mathrm{O}$ ensino médio começou a ser avaliado a partir de 1998 e, em 2001 e 2002, sofreu interrupção, voltando a ser objeto de análise no ano de 2003. 
Tabela 10 - Distribuição dos interesses por níveis de ensino

\begin{tabular}{|l|c|l|}
\hline $\begin{array}{l}\text { Nível de ensino de } \\
\text { interesse }\end{array}$ & Número & Autores \\
\hline Ensino fundamental & 20 & $\begin{array}{l}\text { Oliveira (1998); Esteves (1998); Felipe (1999); Valle } \\
\text { (1999); Ribeiro (2001); Túbero (2003); Hernandes (2003); } \\
\text { Teixeira (2005); Prudêncio (2006); Baggio (2006); Souza } \\
\text { (2007); Dorta (2007); Ferreira (2007); Maldonado (2008); } \\
\text { Vaz (2008); Corrêa (2008); Chiste (2009); Girelli (2010); } \\
\text { Clemente (2011); Rodrigues (2011) }\end{array}$ \\
\hline Ensino médio & 7 & $\begin{array}{l}\text { Bosquetti (2002); Barbosa (2005); Sazdjian (2007); } \\
\text { Maruci (2007); Silva (2007); Chiste (2009); Lugli (2011); } \\
\text { Rodrigues (2011) }\end{array}$ \\
\hline
\end{tabular}

Fonte: Os autores (2014).

Os autores que versam sobre o SARESP e seu amplo universo apresentam preferências relacionadas a determinados temas: encontramos pesquisadores com interesse nos efeitos dos resultados do SARESP no contexto escolar; outros se debruçam sobre a constituição das provas do SARESP, relacionadas aos itens das questões, bem como às questões das competências e habilidades; há também os que analisam o SARESP ancorados nos desdobramentos da reforma do Estado.

Para abarcar esses importantes aspectos acerca do SARESP, definimos, a partir dos conteúdos dos estudos analisados, seis eixos temáticos como forma de compreender frequências correlatas de determinadas unidades textuais elementares, bem como suas particularidades.

Conforme a Tabela 11, o eixo "SARESP: seus resultados, impactos e efeitos", apresenta o maior número de trabalhos, 15 no total, seguido pelo eixo "Aspectos técnicos da constituição das avaliações do SARESP", com 11 pesquisas. "As produções dos alunos no SARESP" é o eixo que aparece com sete trabalhos. As pesquisas relacionadas ao eixo "O SARESP como política avaliativa no contexto da reforma do Estado" totalizam quatro trabalhos, assim como o eixo temático "As concepções, táticas e discursos de professores". Contendo um único trabalho, temos o eixo temático "O SARESP e o currículo".

Considerando, evidentemente, as convergências entre as categorias, constatamos uma aproximação maior entre as categorias "Aspectos técnicos da constituição das avaliações do SARESP" e "SARESP: seus resultados, impactos e efeitos", uma vez que ambas se debruçam, de forma prioritária, sobre questões relacionadas ao 
universo de características das provas do SARESP e também sobre seus resultados e efeitos, principalmente nas áreas de Matemática e Língua Portuguesa. As duas categorias juntas somam, conforme a Tabela 11, aproximadamente $61 \%$ dos trabalhos acerca do SARESP. De certa forma, isto caracteriza uma tendência de interesse existente na comunidade acadêmica, em termos de objeto de estudo.

Tabela 11 - Distribuição de eixos temáticos identificados nas teses e dissertações

\begin{tabular}{|l|c|c|}
\hline Eixos temáticos do assunto SARESP & Quantidade & $\%$ \\
\hline SARESP: seus resultados, impactos e efeitos & 15 & 35,7 \\
\hline Aspectos técnicos da constituição das avaliações do SARESP & 11 & 26,1 \\
\hline As produções dos alunos no SARESP & 7 & 16.6 \\
\hline O SARESP como política avaliativa no contexto da reforma do Estado & 4 & 9,5 \\
\hline As concepções, táticas e discursos de professores & 4 & 9,5 \\
\hline O SARESP e o currículo & 1 & 2,4 \\
\hline Total & 42 & 100 \\
\hline
\end{tabular}

Fonte: Os autores (2014).

\section{SARESP: seus resultados, impactos e efeitos}

Essa categoria apresenta pesquisas voltadas à discussão em torno dos resultados, impactos e efeitos do SARESP na dinâmica escolar (Quadro 1).

A pesquisa de Oliveira (1998) apresenta profunda análise dos resultados das edições de 1996 e 1997, bem como dos princípios e pretensões que nortearam a SEESP na implantação do projeto SARESP, além de sua viabilidade funcional e seu potencial de efetividade nos anos de 1996 e 1997.

Esteves (1998) investiga os impactos, transformações e compreensões causadas pelas provas do SARESP nos anos de 1996, 1997 e 1998, em cinco escolas estaduais de ensino fundamental de uma região periférica do município de São Paulo. A pesquisa de Felipe (1999) apresenta análise dos impactos causados pelo SARESP em quatro escolas estaduais pertencentes à jurisdição da Diretoria de Ensino de Caieiras no decorrer da edição de 1998.

A dissertação de Túbero (2003) investiga o impacto causado pelos resultados do SARESP edição 2000, bem como possíveis mudanças nas práticas pedagógicas, 
relacionadas a alunos negros de escolas estaduais da região de Piracicaba. Machado (2003) também analisa o SARESP edição de 2000. A autora investiga a utilização dos resultados como instrumento para direcionar as ações de diretorias de ensino, com vistas à qualidade do ensino público paulista.

O trabalho de Hernandes (2003) versa sobre aspectos de aproximação e de contradição entre as teorias sobre avaliação de aprendizagem existentes e os objetivos e procedimentos adotados pelos gestores educacionais no ambiente da adoção do SARESP como, segundo a autora, principal meio de avaliação do sistema público do ensino paulista. A autora explora as avaliações de 2001 marcadas, principalmente, pelo papel decisório de aprovação, ou não, dos alunos.

Silva (2006) pondera sobre as principais características das avaliações aplicadas pelo SARESP, de 1996 a 2006, bem como seus efeitos em relação às negociações com os atores envolvidos nesse contexto, objetivando compreender quais as características da educação contempladas na referida avaliação.

Bauer (2006) analisa a utilização dos resultados do SARESP nas políticas de formação docente. Freire (2008) aborda as vicissitudes provocadas pelo SARESP na dinâmica de uma escola estadual da Grande São Paulo, bem como as articulações da escola com a SEESP. Arcas (2009) apresenta investigação sobre as implicações da progressão continuada e do SARESP na avaliação escolar. O autor observa que a progressão continuada tende a influenciar mais o discurso do que as práticas avaliativas e enfrenta maior resistência dos professores, e que o SARESP, por sua vez, vem gradualmente assumindo o papel de orientador de práticas escolares.

Chiste (2009) verifica a eficiência pedagógica da reestruturação do ensino por meio de avaliações de rendimento escolar. A autora toma como base duas escolas que receberam melhores pontuações em Matemática, com base no relatório do SARESP/2007. A pesquisa de Rahal (2010) estuda o SARESP objetivando a compreensão dos efeitos dessa política na qualidade da educação. A autora explora, a partir de sua história de vida, o que denomina como processos de exclusão ao qual são submetidos parte dos alunos e ela própria.

Clemente (2011) analisa os resultados do SARESP no componente curricular de Matemática no ensino fundamental de uma escola estadual no interior de São Paulo. Pinto (2011) estuda os impactos do SARESP na prática profissional 
docente sob o ponto de vista de professores de Língua Portuguesa e Matemática de uma escola estadual paulista no período de 2007 a 2010. Já a pesquisa de Rodrigues (2011) identifica, na opinião de professores da rede estadual, eventuais repercussões no cotidiano da sala de aula, a partir dos resultados do SARESP.

\section{Quadro 1 - Distribuição dos autores na categoria "SARESP: seus resultados, impactos e efeitos"}

\begin{tabular}{|c|c|c|}
\hline Nome do autor & Título & $\begin{array}{l}\text { Ano da } \\
\text { defesa }\end{array}$ \\
\hline $\begin{array}{l}\text { Duzolina Alfredo Felipe } \\
\text { de Oliveira }\end{array}$ & Uma avaliação política do projeto SARESP & 1998 \\
\hline $\begin{array}{l}\text { Maria Eunice de Paiva } \\
\text { Pinto e Esteves }\end{array}$ & $\begin{array}{l}\text { Sistema de Avaliação de Rendimento Escolar do } \\
\text { Estado de São Paulo - SARESP: uma ação planejada }\end{array}$ & 1998 \\
\hline Jesse Pereira Felipe & $\begin{array}{l}\text { Uma análise crítica do Sistema de Avaliação de Ren- } \\
\text { dimento Escolar do Estado de São Paulo - SARESP }\end{array}$ & 1999 \\
\hline Rosana Túbero & $\begin{array}{l}\text { O Sistema de Avaliação de Rendimento Escolar do } \\
\text { Estado de São Paulo e os alunos negros das escolas } \\
\text { estaduais da região de Piracicaba }\end{array}$ & 2003 \\
\hline $\begin{array}{l}\text { Elianeth Dias Kanthack } \\
\text { Hernandes }\end{array}$ & $\begin{array}{l}\text { Os propósitos e os impactos causados em uma } \\
\text { escola da região de Assis pela implantação e pelas } \\
\text { mudanças de rumo do SARESP }\end{array}$ & 2003 \\
\hline Cristiane Machado & Avaliar as escolas estaduais para quê? & 2003 \\
\hline $\begin{array}{l}\text { Hilda Maria Gonçalves da } \\
\text { Silva }\end{array}$ & $\begin{array}{l}\text { Gestão educacional e sistemas de avaliação: os pres- } \\
\text { supostos ideológicos do SARESP e a trajetória das } \\
\text { avaliações aplicadas entre } 1996 \text { e } 2005\end{array}$ & 2006 \\
\hline Adriana Bauer & $\begin{array}{l}\text { Usos dos resultados do SARESP: o papel da avalia- } \\
\text { ção nas políticas de formação docente }\end{array}$ & 2006 \\
\hline $\begin{array}{l}\text { Lilian Rose da Silva Car- } \\
\text { valho Freire }\end{array}$ & $\begin{array}{l}\text { Saresp 2005: as vicissitudes da avaliação em uma } \\
\text { escola da rede estadual }\end{array}$ & 2008 \\
\hline Paulo Henrique Arcas & $\begin{array}{l}\text { Implicações da progressão continuada e do SARESP } \\
\text { na avaliação escolar: tensões, dilemas e tendências }\end{array}$ & 2009 \\
\hline Monica Cristina Chiste & $\begin{array}{l}\text { Sistema de Avaliação do Rendimento Escolar do } \\
\text { Estado de São Paulo: repercussão do resultado } \\
\text { positivo em duas escolas no ano de } 2007\end{array}$ & 2009 \\
\hline Soraya Rahal & $\begin{array}{l}\text { Políticas públicas de Educação: o SARESP no coti- } \\
\text { diano escolar }\end{array}$ & 2010 \\
\hline Cesar Clemente & $\begin{array}{l}\text { Os desdobramentos do SARESP no processo } \\
\text { curricular e na avaliação interna: uma análise do } \\
\text { componente curricular de Matemática }\end{array}$ & 2011 \\
\hline $\begin{array}{l}\text { Márcio Alexandre Ra- } \\
\text { vagnani Pinto }\end{array}$ & $\begin{array}{l}\text { Política pública e avaliação: o Saresp e seus impac- } \\
\text { tos na prática profissional docente }\end{array}$ & 2011 \\
\hline $\begin{array}{l}\text { Rodrigo Ferreira Rodri- } \\
\text { gues }\end{array}$ & $\begin{array}{l}\text { Usos e repercussões de resultados do SARESP na } \\
\text { opinião de professores da rede estadual paulista }\end{array}$ & 2011 \\
\hline
\end{tabular}

Fonte: Os autores (2014). 


\section{Aspectos técnicos da constituição das avaliações do SARESP}

O foco dessa categoria é a constituição das avaliações do SARESP: seus itens, teorias inseridas, componentes das provas, características das avaliações, exames de textos relacionados, principalmente Matemática e Língua Portuguesa (Quadro 2).

Os conceitos básicos da teoria da resposta ao item (TRI), bem como suas aplicações em avaliações educacionais brasileiras, é o objeto de estudo de Valle (1999), tomando como referência as edições de 1996 e 1997 do SARESP.

São três os estudos que revelam preocupações com questões referentes à geometria espacial e conteúdos sobre estatística. Bosquetti (2002) pondera sobre as questões do SARESP para o $3^{\circ}$ ano do ensino fundamental na edição de 2000 , relacionadas às condições de visualização em geometria espacial. A pesquisa de Silva (2007) verifica as relações entre instrumentos educacionais brasileiros: livros didáticos, documentos oficiais e os exames oficiais (SAEB, ENEM e SARESP), especificamente no que diz respeito aos conteúdos de estatística, à luz dos níveis de alfabetização estatística propostos por alguns especialistas, entre eles: Iddo Gal, Maxine Pfannkuch e Chris J. Wild. O estudo de Lugli (2011) analisa as questões relacionadas aos raciocínios (combinatório, estatístico e probabilístico) propostas nas avaliações externas de ENEM e SARESP, no período compreendido entre 2007 e 2009.

São sete os trabalhos que se debruçam no campo da leitura e escrita. Mesko (2004) analisa os itens das provas de Língua Portuguesa e de Leitura e Escrita do SARESP, com o objetivo de debater as concepções de leitura e de aluno letrado, relacionadas ao trabalho com a linguagem inserido nessas avaliações. A pesquisa de Barbosa (2005), em um contexto mais amplo, analisa a atividade de avaliar do SARESP nas escolas públicas paulistas, focando o desenvolvimento das habilidades de leitura e escrita dos alunos, a partir do ensino de gêneros textuais.

Augusto (2006) examina, na área de Língua Portuguesa (redação), textos dissertativo-argumentativos trabalhados no SARESP, para verificação das condições desses textos na direção de subsidiar os estágios da estrutura problema-solução. A dissertação de Souza (2007) busca compreender os possíveis motivos dos alunos nas dificuldades com inferência, a partir da análise de textos e questões do SARESP, edições de 2003 e 2004. 
Maruci (2007) investiga os efeitos, a validade e a legitimidade da prova de Leitura e Escrita do SARESP do $2^{\circ}$ ano do período noturno, elaborada a partir de elementos de competências e habilidades. Ferreira (2007) examina as provas de Leitura e Escrita da $4^{a}$ série do ensino fundamental das edições de 1997, 2002 e 2005, pesquisando os limites e possibilidades das provas em face do objetivo proposto, que é avaliar a habilidade leitora e a qualidade do ensino. O trabalho de Maldonado (2008) analisa as provas referentes aos gêneros textuais do SARESP das edições de 2003, 2004 e 2005, na direção de compreender questões concernentes à leitura e interpretação de textos.

\section{Quadro 2 - Distribuição dos autores na categoria "Aspectos técnicos da constituição das avaliações do SARESP"}

\begin{tabular}{|l|l|c|}
\hline Nome do autor & Título & $\begin{array}{c}\text { Ano da } \\
\text { defesa }\end{array}$ \\
\hline Raquel da Cunha Valle & Teoria da resposta ao item & 1999 \\
\hline $\begin{array}{l}\text { Maria Carolina Bonna } \\
\text { Bosquetti }\end{array}$ & $\begin{array}{l}\text { SARESP/2000 e a questão da visualização em } \\
\text { geometria espacial }\end{array}$ & 2002 \\
\hline $\begin{array}{l}\text { Wladimir Stempniak } \\
\text { Mesko }\end{array}$ & $\begin{array}{l}\text { Questões de leitura no Sistema de Avaliação do } \\
\text { Rendimento Escolar do Estado de São Paulo }\end{array}$ & 2004 \\
\hline Geraldo Carlos Barbosa & A atividade de avaliar no Saresp & 2005 \\
\hline $\begin{array}{l}\text { Fabiana de Fátima } \\
\text { Augusto }\end{array}$ & $\begin{array}{l}\text { A produção e a compreensão de um texto } \\
\text { dissertativo-argumentativo: a estrutura problema- } \\
\text {-solução nas redações do SARESP }\end{array}$ & 2006 \\
\hline Iranéia Loiola de Souza & $\begin{array}{l}\text { A competência leitora na perspectiva do SARESP: a } \\
\text { habilidade de inferir informação implícita em texto } \\
\text { escrito }\end{array}$ & 2007 \\
\hline $\begin{array}{l}\text { Fátima Aparecida de } \\
\text { Souza Maruci }\end{array}$ & $\begin{array}{l}\text { Leitura e escrita: análise de uma proposta de ava- } \\
\text { liação por competências e habilidades }\end{array}$ & 2007 \\
\hline Júlio César da Silva & $\begin{array}{l}\text { Conhecimentos estatísticos e os exames oficiais: } \\
\text { SAEB, ENEM e SARESP }\end{array}$ & 2007 \\
\hline Roseli Helena Ferreira & $\begin{array}{l}\text { O Sistema de Avaliação do Rendimento Escolar } \\
\text { do Estado de São Paulo (SARESP): uma análise } \\
\text { das provas de Leitura e Escrita da quarta série do } \\
\text { ensino fundamental }\end{array}$ & 2007 \\
\hline donado & $\begin{array}{l}\text { SARESP e diversidade textual: perspectivas na } \\
\text { formação do leitor }\end{array}$ & $\begin{array}{l}\text { A análise de dados e a probabilidade nas ava- } \\
\text { liações externas para o ensino médio: ENEM e } \\
\text { SARESP }\end{array}$ \\
\hline
\end{tabular}

Fonte: Os autores (2014). 


\section{As produções de alunos no SARESP}

Nessa categoria, os trabalhos exploram questões acerca das produções e desenvolvimento dos alunos; assim, são analisados procedimentos e estratégias utilizados para a resolução das questões relativas às provas do SARESP nas áreas de Matemática e Língua Portuguesa, com ênfase na análise das questões relacionadas às produções dos alunos nesta última área (Quadro 3).

Ribeiro (2001) analisa em seu trabalho os procedimentos e estratégias que alunos da $8^{a}$ série do ensino fundamental utilizaram para resolver questões de Álgebra, na edição de 1997. A partir de análises de questões de Matemática do SARESP, edição 2005, Vaz (2008) busca compreender o desempenho dos alunos da $7^{\mathrm{a}}$ série do ensino fundamental, com vistas à conversão do registro de representação semiótica da língua natural para registro algébrico.

A pesquisa de Gutierre (2003) tem foco na produção de redações promovidas pelo SARESP. O trabalho de Teixeira (2005) verifica a interação indireta entre os usuários da língua natural, para compreender como os alunos da $8^{\mathrm{a}}$ série de escolas da cidade de São José do Rio Preto produzem sentido ao resolverem uma avaliação com questões de múltipla escolha.

Prudêncio (2006) avalia o desenvolvimento de vocabulário receptivo-auditivo, a consciência fonológica, a competência de leitura e escrita, relacionadas à prova de português do SARESP, edição de 2002. A pesquisa de Dorta (2007) evidencia a produção de textos de alunos de $4^{\mathrm{a}}$ e $8^{\mathrm{a}}$ séries do ensino fundamental, buscando verificar o domínio dos alunos relacionado ao gênero textual, a partir de suas expressões escritas.

Sazdjian (2007) apresenta interesse no exame de textos argumentativos produzidos por alunos da $3^{\mathrm{a}}$ série, período noturno, do ensino médio da rede pública estadual. A pesquisadora analisou 20 produções dos alunos e fundamentou-se, principalmente, na estrutura problema-solução e na linguística sistêmico-funcional. 


\section{Quadro 3 - Distribuição dos autores na categoria “As produções de alunos no SARESP"}

\begin{tabular}{|c|c|c|}
\hline Nome do autor & Título & $\begin{array}{l}\text { Ano da } \\
\text { defesa }\end{array}$ \\
\hline $\begin{array}{l}\text { Alessandro Jacques } \\
\text { Ribeiro }\end{array}$ & $\begin{array}{l}\text { Analisando o desempenho de alunos do ensino } \\
\text { fundamental em Álgebra, com base em dados do } \\
\text { SARESP }\end{array}$ & 2001 \\
\hline $\begin{array}{l}\text { Maria Madalena Borges } \\
\text { Gutierre }\end{array}$ & $\begin{array}{l}\text { Heterogeneidade nas redações escolares: a res- } \\
\text { posta dos alunos ao SARESP }\end{array}$ & 2003 \\
\hline $\begin{array}{l}\text { Maria Luiza de Sousa } \\
\text { Teixeira }\end{array}$ & $\begin{array}{l}\text { A construção de sentidos na avaliação de múltipla } \\
\text { escolha do SARESP }\end{array}$ & 2005 \\
\hline Erica Relvas Prudêncio & $\begin{array}{l}\text { Desenvolvimento de vocabulário receptivo, } \\
\text { consciência fonológica, leitura e escrita de } 1^{a} \text { a } \\
4^{\mathrm{a}} \text { série do ensino fundamental público, e relação } \\
\text { com o desempenho na prova de Português do } \\
\text { Saresp-2002 (Sistema de Avaliação de Rendimen- } \\
\text { to Escolar do Estado de São Paulo) }\end{array}$ & 2006 \\
\hline $\begin{array}{l}\text { Roseli Aparecida Franco } \\
\text { Dorta }\end{array}$ & $\begin{array}{l}\text { A produção textual de alunos de } 4^{a} \text { e } 8^{a} \text { séries } \\
\text { do ensino fundamental no Saresp - Sistema de } \\
\text { Avaliação do Rendimento Escolar do Estado de } \\
\text { São Paulo }\end{array}$ & 2007 \\
\hline Anaid Bertezlian Sazdjian & $\begin{array}{l}\text { As redações do SARESP: o texto argumentativo e } \\
\text { a análise das três pontas }\end{array}$ & 2007 \\
\hline $\begin{array}{l}\text { Rosana Aparecida da } \\
\text { Costa Vaz }\end{array}$ & $\begin{array}{l}\text { SARESP/2005: uma análise de questões de Mate- } \\
\text { mática da } 7^{a} \text { série do ensino fundamental, sob a } \\
\text { ótica dos níveis de mobilização de conhecimentos } \\
\text { e dos registros de representação semiótica }\end{array}$ & 2008 \\
\hline
\end{tabular}

Fonte: Os autores (2014).

\section{O SARESP como política avaliativa no contexto da reforma do Estado}

Os trabalhos pertencentes a esse eixo temático, e relacionados no Quadro 4, direcionam suas atenções, de maneira geral, à analise do SARESP enquanto política avaliativa no contexto da reforma do Estado e seus desdobramentos; sua relação com o desenvolvimento da avaliação no Estado de São Paulo; sua gestão, em nível de secretaria de Educação estadual e escolas, ponderando medidas políticas e administrativas de sua implantação. Há forte tendência de análise, que arrola o SARESP às orientações neoliberais, principalmente na década de 1990. 
A pesquisa de Ceneviva (2006) discute o papel que a institucionalização de sistemas de avaliação de programas e políticas pode desempenhar na criação ou aperfeiçoamento de mecanismos de responsabilização (accountability). Para o desenvolvimento de tal análise, o SARESP, bem como o Programa Estadual DST/AIDS, ganha protagonismo.

Ribeiro (2008), baseando-se no SARESP e nas políticas educacionais do Estado de São Paulo, explicita em seu trabalho a relação normativa da regulação estatal por meio da avaliação, no período de 1990 a 2007. Alcântara (2010) verifica a possibilidade de se estabelecer relação entre ações e/ou reformas da SEESP e as estratégias neoliberais para os países em desenvolvimento, no período de 1996 a 2009.

Já Camba (2011) analisa a trajetória da elaboração e implementação da política de avaliação no Brasil, no período de 1995 a 2009, com foco no SARESP. A autora percorre o processo da política, em nível estadual e nacional, contextualizando a temporalidade com o que denomina de "onda" das políticas de avaliação.

\section{Quadro 4 - Distribuição dos autores na categoria "O SARESP como política} avaliativa no contexto da reforma do Estado"

\begin{tabular}{|l|l|c|}
\hline Nome do autor & Título & $\begin{array}{c}\text { Ano da } \\
\text { defesa }\end{array}$ \\
\hline Ricardo Ceneviva & $\begin{array}{l}\text { Democracia, accountability e avaliação: a avaliação } \\
\text { de políticas públicas como instrumento de controle } \\
\text { democrático }\end{array}$ & 2006 \\
\hline Denise da Silva Ribeiro & $\begin{array}{l}\text { Avaliação do Rendimento Escolar do Estado de São } \\
\text { Paulo (SARESP): a educação a serviço do capitalismo }\end{array}$ & 2008 \\
\hline $\begin{array}{l}\text { Melina Sant'Anna } \\
\text { Alcântara }\end{array}$ & $\begin{array}{l}\text { Políticas de bonificação e indicadores de qualidade: } \\
\text { mecanismos de controle nas escolas estaduais paulistas }\end{array}$ & 2010 \\
\hline Mariângela Camba & $\begin{array}{l}\text { As políticas de avaliação do rendimento escolar e as } \\
\text { interfaces na esfera nacional e estadual: análise do } \\
\text { Saresp como política de avaliação no estado de São } \\
\text { Paulo, Brasil }\end{array}$ & 2011 \\
\hline
\end{tabular}

Fonte: Os autores (2014).

\section{As concepções, táticas e discursos dos professores}

Nessa categoria, os autores buscam compreender os discurso e concepções produzidos por professores sobre o SARESP, e questões vinculadas às 
práticas pedagógicas em torno dessa avaliação (Quadro 5). A preocupação dos pesquisadores sobre as concepções e discursos de professores direciona-se, em maior medida, para o ensino fundamental.

Kawauchi (2001) foca seu trabalho em questões como promoção do repensar da prática pedagógica e melhoria da qualidade da educação, principalmente no entendimento de professores da rede estadual acerca do SARESP, especialmente sobre o ensino de História. Baggio (2006) analisa o discurso dos professores, a partir do mau desempenho de alunos concluintes do ciclo I do ensino fundamental no SARESP.

Corrêa (2008) pesquisa as concepções de prática pedagógica de professores de Matemática da 5 a série do ensino fundamental da Diretoria de Ensino da Região de Presidente Prudente. Alves (2011) investiga como professores de escolas classificadas diferentemente pelo estado agem sob os efeitos do SARESP. Para visualizar as produções desses sujeitos, o autor utiliza a perspectiva de Michel de Certeau.

\section{Quadro 5 - Distribuição dos autores na categoria “As concepções, táticas e discursos de professores"}

\begin{tabular}{|l|l|l|}
\hline Nome do autor & Título & $\begin{array}{l}\text { Ano da } \\
\text { defesa }\end{array}$ \\
\hline Mary Kawauchi & SARESP e ensino de História: algumas questões & 2001 \\
\hline $\begin{array}{l}\text { Silvia Cristina } \\
\text { Rossito Baggio }\end{array}$ & $\begin{array}{l}\text { Política educacional, Saresp e discurso de professores: } \\
\text { vozes constituídas e constituintes de um sistema e a } \\
\text { subjetividade dos professores }\end{array}$ & 2006 \\
\hline Laura Maria Corrêa & $\begin{array}{l}\text { As concepções de professores de Matemática de 5a } \\
\text { série do ensino fundamental sobre sua prática e os } \\
\text { resultados do SARESP 2005 }\end{array}$ & 2008 \\
\hline $\begin{array}{l}\text { Caio Augusto } \\
\text { Carvalho Alves }\end{array}$ & Táticas docentes frente aos efeitos do SARESP & 2011 \\
\hline
\end{tabular}

Fonte: Os autores (2014).

\section{O SARESP e o currículo}

A categoria "O SARESP e o currículo", formada pelo trabalho de apenas um autor, Girelli (2010), apresenta uma análise bastante aprofundada sobre 
a construção e o funcionamento do currículo que, por sua vez, relacionase com as provas do SARESP e também com os resultados obtidos pelos alunos e suas realidades. Entre os trabalhos do SARESP, encontramos autores que ponderam sobre questões ligadas ao currículo, mas tratam o tema numa perspectiva diferente de Girelli (2010). É o caso de Clemente (2011), que analisa os resultados e desdobramentos do SARESP no componente curricular de Matemática, objetivando identificar a concepção de professores entre avaliação interna e externa, bem como as mudanças ocasionadas pelo SARESP na avaliação interna e prática curricular. A adoção dessa perspectiva fez com que o trabalho de Clemente esteja enquadrado na categoria SARESP: seus resultados, impactos e efeitos.

Quadro 6 - Distribuição dos autores na categoria "O SARESP e o currículo"

\begin{tabular}{|l|l|c|}
\hline Nome do autor & Título & Ano da defesa \\
\hline Heitor Girelli & $\begin{array}{l}\text { Currículo e cultura: elementos do fracasso escolar. } \\
\text { Um estudo com base nas provas do SARESP e } \\
\text { FUVEST }\end{array}$ & 2010 \\
\hline
\end{tabular}

Fonte: Os autores (2014).

\section{Considerações finais}

Por meio do presente mapeamento, observamos, entre as 42 teses e dissertações selecionadas, que as pesquisas em torno do SARESP, desde 1998 - ano do primeiro trabalho sobre essa avaliação (OLIVEIRA, 1998), apresentam regularidade, com tendência crescente nos números de pesquisas realizadas até o ano de 2011. Os pesquisadores, conforme a configuração dos eixos temáticos, apresentam empenhos em maior medida para as questões relacionadas aos resultados, impactos e efeitos decorrentes do referido sistema de avaliação.

Esses interesses têm grande importância porque a avaliação em larga escala, notadamente a partir do Saeb, ganhou centralidade nas políticas educacionais, como forma de aprimorar a qualidade no setor da educação, colaborando, também, para uma nova "cultura de avaliação" em nosso país. Essas transformações, respaldadas, especialmente, pelos desdobramentos da reforma do Estado no Brasil, foram tratadas, por muitos pesquisadores, de forma consideravelmente ampla pelas temáticas apreendidas aqui, ponderando, ainda, o quanto a reforma educacional brasileira, nas últimas décadas, 
implicou, entre outras questões, em ações envolvendo uma super valorização dos resultados concernentes às avaliações em larga escala, responsabilização, performatividade, bonificações e ranqueamento.

Assim ganham sentido também as apreensões de muitos pesquisadores em direção dos aspectos técnicos da constituição das avaliações do SARESP e as produções dos alunos, especialmente nas áreas de português e matemática.

Preocupações com as concepções, discursos e táticas dos professores relacionados ao SARESP estão presentes também entre as teses e dissertações analisadas, tendo em vista que, além das alterações objetivas que as últimas reformas na educação brasileira proporcionaram, ocorreram ainda mudanças subjetivas atinentes aos professores.

Apesquisa realizada permite identificar alguns silêncios temáticos em torno desse sistema avaliativo, entre eles: as apropriações da mídia atinentes aos resultados dos alunos, notadamente, em muitas situações cercadas de equívocos e ausência de profundidade sobre os sentidos da avaliação na escola; as apropriações dos pais sofre o SARESP, tendo em vista a importância desse público no contexto escolar; os processos comunicacionais entre o comando do governo paulista e públicos da escola, principalmente professores; e um aprofundamento dos sentidos do accountability, princípio gerencial utilizado pelo governo de forma, muitas vezes, aquém do que exige um ambiente democrático, considerando principalmente exigências legítimas da sociedade, que evolvem questões relacionadas à prestação de contas.

Decerto, se podemos, atualmente, compreender algumas rupturas, aprimoramentos, contextos e impactos relacionados ao SARESP, isso ocorre pelo esforço de pesquisadores vinculados a 14 importantes instituições formadoras de mestres e/ ou doutores, orientados por docentes-pesquisadores de grande destaque no cenário educacional brasileiro, como Isabel Franchi Cappelletti, Sumiko Nishitani Ikeda e Sandra M. Zakia Lian Sousa.

Embora tenha sido objeto de estudo, em diversos Programas de PósGraduação, chegando a ter uma abrangência multidisciplinar, o SARESP tem chamado a atenção de três áreas prioritárias: Educação, Linguística e Língua, e Matemática, envolvendo múltiplos olhares e abordagens teórico- 
metodológicas. Como didaticamente afirma Gomes (2005), as teorias envolvem diversas maneiras de enfocar a mesma realidade, podendo existir diferentes visões do mesmo edifício, dependendo o lugar do qual é abordado, da calçada, do telhado ou de um helicóptero.

Entretanto, a pesquisa realizada permitiu identificar o que, no âmbito acadêmicocientífico, se convencionou chamar de Serendipidade (serendipity), isto é, "a faculdade de fazer descobertas interessantes por acaso, quando em busca de outra coisa" (OLIVEIRA, 2011, p. 532). O que foi que constatamos ou descobrimos? A predominância de ponderações teóricas, nas teses e dissertações analisadas, que acenam para o alinhamento do SARESP com o atendimento dos ditames neoliberais (ALCÂNTARA, 2010; GIRELLI, 2010; CAMBA, 2011; PINTO, 2011), legitimadores da sociedade capitalista e dos valores e das estratégias do mercado e das empresas na educação (BAGGIO, 2006; SILVA, 2006; ALVES, 2010), "uma política educacional voltada para a escola estatal, educação a serviço do capitalismo, em detrimento da constituição de uma escola pública voltada aos reais interesses [... dos que] dela tanto esperam" (RIBEIRO, 2008, p. 199), uma política que, a partir da sua intencionalidade, não contribui com a perspectiva de construção de uma escola pública de qualidade. (MACHADO, 2003)

Nessa ótica, o Banco Mundial é visto como o grande elemento indutor das práticas de tais ideologias, tanto em estudos elaborados no final da década de 1990 (FELIPE, 1999), como recentemente, no início da segunda década de 2000 (RAHAL, 2010). A utilização da avaliação externa por meio de competências e habilidades pré-determinadas é colocada, em grande medida, como parte de uma estratégia para atender as orientações legitimadoras dos valores neoliberais, bem como instrumentalizar os alunos em atendimento às leis do mercado e consumo.

Apesar de serem estudados diversos aspectos teóricos e técnico-operacionais do SARESP, podemos afirmar que se constata uma mesma episteme predominante que sustenta e unifica a maioria dos estudos analisados. Entendemos por episteme, na mesma perspectiva Foucaultiana, um "conjunto das relações que podem unir, em uma dada época, as práticas discursivas que dão lugar a figuras epistemológicas, a ciências, eventualmente a sistemas formalizados" (FOUCAULT, 2008, p. 214). Trata-se de conjunto de relações "que podem ser descobertas, para uma época dada, entre as ciências, quando estas são analisadas no nível das regularidades discursivas" (FOUCAULT, 2008, p. 214). 
Essa episteme emoldura inclusive estudos que abordam aspectos mais técnicos nas áreas de leitura e escrita, por citar um exemplo, Maruci (2007), ao abordar a avaliação da leitura e escrita na lógica das competências e habilidades, afirma que essa se insere "no ideário neoliberal do discurso da formação para o desenvolvimento da autonomia e da flexibilidade, no processo de escolarização para adaptação às inovações tecnológicas e às leis do mercado" (MARUCI, 2007, p. 96). Numa tônica semelhante, Ferreira (2007), ao estudar as provas de leitura e escrita, conclui que as concepções de competência, habilidade e leitura do SARESP "estão vinculados aos ideais neoliberais", pretendendo-se "formar leitores, em termos de instrumentalizá-los para o cotidiano imediato, para produzir e consumir mais" (FERREIRA, 2007, p. 148).

A pesquisa realizada permite apostar na existência de uma comunidade epistêmica, que na concepção de Haas (1992), implica na existência de uma rede de profissionais com reconhecida especialização e competência num domínio específico que afirmam sua autoridade sobre conhecimento politicamente relevante dentro daquele domínio ou área. Para Haas (1992), embora uma comunidade possa estar composta por profissionais de diversas áreas, elas compartilham um conjunto comum de crenças, normas e princípios, provendo uma racionalidade valorativa na ação de seus membros, que no caso de nosso objeto de estudo, envolve questões valorativas sobre os aspectos negativos que envolvem as estratégias da sociedade capitalista por meio da expansão e ditames neoliberais na educação.

Outros aspectos compartilhados pela comunidade epistêmica, conforme Haas (1992), dizem respeito às crenças a respeito das relações causais para problemas, servindo de base para a ação política e os resultados desejáveis; às noções de validade partilhadas, critérios intersubjetivos, para avaliar e validar conhecimento no domínio de sua especialidade; e a um empreendimento político comum, um conjunto de práticas associadas com um conjunto de problemas aos quais se direciona sua competência profissional, com a convicção do bem-estar que a humanidade poderá obter em decorrência do direcionamento adotado. Todos esses aspectos permitem compreender a consonância existente nessa comunidade epistêmica, em torno da origem do SARESP e as estratégias neoliberais impulsionadas pelo Banco Mundial que, ao deter uma valoração negativa, impulsiona discursos de negação dessa realidade. 
A comunidade epistêmica hegemônica, no estudo e compreensão do SARESP, revela, assim, uma dimensão política, dentro do que se convencionou chamar de paradigma do conflito, caracterizada no campo da educação por "empreender uma crítica radical do pensamento pedagógico liberal” (SANDER, 1984, p. 76), uma crítica a partir da qual emergem teses para a ação política.

Dessa forma, a adoção da comunidade epistêmica como mediação analítica e interpretativa permite constatar a acentuada crítica recebida pelo SARESP, dentro de um arcabouço discursivo que ressalta sua negatividade, como observamos nas conclusões de Alcântara (2010, p. 85):

As ações implantadas pela SEESP devem ser analisadas em conjunto, uma vez que representam estratégias de manipulação e de convencimento direcionadas a toda uma classe de profissionais: o professorado e, conseqüentemente, a uma instituição de expressiva relevância social: a escola.

A hegemonia das idéias da comunidade epistêmica mencionada não significa homogeneização das narrativas, existem teses e dissertações, embora em termos pouco expressivos, que se distanciam totalmente desses discursos de verdade. Este tipo de abordagem se concentra nos aspectos técnicos e operacionais do SARESP, podemos citar, por exemplo, a pesquisa de Vaz (2008), que analisou o desempenho dos alunos na resolução de questões do SARESP relacionadas à Álgebra, o estudo de Lugli (2001) que analisou as provas do SARESP para verificar os conceitos de combinatória, probabilidade e estatística solicitados aos alunos do ensino médio, a dissertação de Ribeiro (2001), que estudou as razões para o insucesso revelado no desempenho dos alunos em Álgebra, e a pesquisa de Dorta (2007), entre outras, que buscou critérios mais esclarecedores para uma análise dos textos produzidos por alunos nas avaliações externas. Trata-se de estudos focados mais na compreensão e aprimoramento do SARESP, que didaticamente podem ser englobados dentro do paradigma do consenso que, conforme Sander (1984) acena para uma preocupação na busca do equilíbrio, da ordem, da eficiência do sistema dentro de uma lógica da racionalidade instrumental.

Como aponta Gomes (2005, p. 31), o caráter didático da existência desses dois paradigmas na sociologia da educação, apresenta como um inconveniente, o perigo inerente a toda generalização, uma vez que "alguns autores baseiam- 
se ao mesmo tempo nos paradigmas do consenso e do conflito". Nessa pesquisa, localizamos estudos que questionam e transitam entre os dois paradigmas, constatamos estudos que realizam análises institucionais focados na compreensão dos processos para o aprimoramento das políticas públicas (CENEVIVA, 2006), alguns deles com explícita defesa da avaliação formativa em oposição às avaliações classificatórias (ARCAS, 2009), outras mostrando estratégias equivocadas reveladas na compreensão dos usos dos resultados dos SARESP (BAUER, 2006) ou, inclusive, efeitos positivos acerca dessa avaliação nas unidades escolares (CHISTE, 2009).

\section{Referências}

ALCÂNTARA, M. S. Políticas de bonificação e indicadores de qualidade: mecanismos de controle nas escolas estaduais paulistas. 2010. Dissertação (Mestrado)-Faculdade de Educação, Pontifícia Universidade Católica de São Paulo, São Paulo, 2010.

ALVES, C. A. C. Táticas docentes frente aos efeitos do SARESP. 2011. Dissertação (Mestrado)-Escola de Filosofia, Letras e Ciências Humanas, Universidade Federal de São Paulo, Guarulhos, 2011.

ANDRADE, D. F. de. Desempenhos de grupos de alunos por intermédio da Teoria de Resposta ao Item. Estudos em Avaliação Educacional, [S.1.], n. 23, p. 31-70, 2001.

ARCAS, P. H. Implicações da progressão continuada e do SARESP na avaliação escolar: tensões, dilemas e tendências. 2009. Tese (Doutorado)-Faculdade de Educação, Universidade de São Paulo, São Paulo, 2009.

ARCAS, P. H. Saresp e progressão continuada: implicações na avaliação escolar. Estudos em Avaliação Educacional, São Paulo, v. 21, n. 47, p. 473-488, set./dez. 2010.

AUGUSTO, F. de F. A produção e a compreensão de um texto dissertativoargumentativo: a estrutura problema-solução nas redações do SARESP. 2006. Dissertação (Mestrado) - Pós-Graduação em Linguística Aplicada e Estudos da Linguagem, Pontifícia Universidade Católica de São Paulo, São Paulo, 2006. 
BAGGIO, S. C. R. Política educacional, SARESP e discurso de professores: vozes construídas e constituintes de um sistema e a subjetividade dos professores. 2006. Dissertação (Mestrado)-Departamento de Linguística Aplicada, Universidade de Taubaté, Taubaté, 2006.

BARBOSA, G. C. A atividade de avaliar no SARESP. 2005. Dissertação (Mestrado)-Progama de Pós-Graduação em Linguística Aplicada e Estudos da Linguagem, Pontifícia Universidade Católica de São Paulo, São Paulo, 2005.

BAUER, A. Uso dos resultados do SARESP: o papel da avaliação nas políticas de formação docente. 2006. Dissertação (Mestrado)-Progama de Pós-Graduação em Educação, Universidade de São Paulo, São Paulo, 2006.

Avaliação de impacto no Brasil: é possível mensurar impactos de programas de formação docente? Estudos em Avaliação Educacional, [S. 1.], v. 21, n. 46, p. 229-251, 2010.

. Uso dos resultados do Saresp e formação de professores: a visão dos níveis centrais. Estudos em Avaliação Educacional, [S. 1.], v. 19, n. 41, p. 483498, 2008.

. Formação continuada de professores e resultados dos alunos no SARESP: propostas e realizações. Estudos em Avaliação Educacional, [S. 1.], v. 37, n. 4, p.809-824, 2011.

BOSQUETTI, M. C. B. SARESP/2000 e a questão da visualização em geometria espacial. 2002. (Mestrado)-Progama de Pós-Graduação em Educação, Pontifícia Universidade Católica de São Paulo, São Paulo, 2002.

CALDERÓN, A. I.; FERREIRA, A. G. Administração da educação no Brasil: um diálogo comparativo com as tendências temáticas da Revista IberoAmericana de Educação. Revista Brasileira de Política e Administração da Educação, Porto Alegre, v. 27, n. 2, p. 321-339, maio/ago. 2011.

CAMBA, M. As políticas de avaliação do rendimento escolar e as interfaces na esfera nacional e estadual: análise do Saresp como política de avaliação no Estado de São Paulo, Brasil. 2011. Tese (Doutorado)-Faculdade de Educação, Universidade Estadual de Campinas, Campinas, 2011. 
CANDAU, V. M; OSWALD, M. L. Avaliação no Brasil: uma revisão bibliográfica. Cadernos de Pesquisa, n. 95, p. 25-36, nov. 1995.

CENEVIVA, C. Democracia, accountability e avaliação: a avaliação de políticas públicas como instrumento de controle democrático. 2006. Dissertação (Mestrado) - Programa de Pós-Graduação em Administração Pública, Fundação Getúlio Vargas, São Paulo, 2006.

CHISTE, M. C. SARESP - Sistema de Avaliação do Rendimento Escolar do Estado de São Paulo: repercussão do resultado positivo em duas escolas no ano de 2007. 2009. Dissertação (Mestrado Profissionalizante em Educação)Pontifícia Universidade Católica de São Paulo, São Paulo, 2009.

CLEMENTE, C. Os desdobramentos do SARESP no processo curricular e na avaliação interna: uma análise do componente curricular de Matemática. 2011. Dissertação (Mestrado em Educação)-Centro Universitário Moura Lacerda, Ribeirão Preto, 2011.

CORRÊA, L. M. As concepções de professores de Matemática de $5^{a}$ série do ensino fundamental sobre sua prática e os resultados do SARESP 2005. 2008. Dissertação (Mestrado em Educação) - Faculdade de Ciências e Tecnologia, Universidade Estadual Paulista "Júlio Mesquita Filho", Presidente Prudente, 2008.

DORTA, R. A. F. A produção textual de alunos de $4^{a}$ e $8^{a}$ séries do ensino fundamental no Saresp - Sistema de Avaliação do Rendimento Escolar do Estado de São Paulo. 2007. Dissertação (Mestrado em Educação)-Universidade São Francisco, Itatiba, 2007.

ESPOSITO, Y. L.; DAVIS, C.; NUNES, M. M. R. Sistema de avaliação do rendimento escolar. O modelo adotado pelo estado de São Paulo. Revista Brasileira de Educação, Rio de Janeiro, n. 13, p. 25-53, jan./fev./mar./abr. 2000.

ESTEVES, E. de. P. P. e. Sistema de Avaliação do Rendimento Escolar do Estado de São Paulo - SARESP: uma ação planejada. 1998. Dissertação (Mestrado em Educação)-Faculdade de Educação, Pontifícia Universidade Católica de São Paulo, São Paulo, 1998. 
FELIPE, J. P. Uma análise crítica do Sistema de Avaliação do Rendimento Escolar do Estado de São Paulo - SARESP. 1999. Dissertação (Mestrado em Educação)- Pontifícia Universidade Católica de São Paulo, São Paulo, 1999.

FERREIRA, N. S. A. As pesquisas denominadas "Estado da Arte". Educação e Sociedade, Campinas, São Paulo, v. 23, n. 79, p. 257-272, 2002.

FERREIRA, R. H. O Sistema de Avaliação de Rendimento Escolar do Estado de São Paulo - SARESP: uma análise das provas de leitura e escrita da $4^{\mathrm{a}}$ série do ensino fundamental. 2007. Dissertação (Mestrado em Educação)-Faculdade de Ciências e Tecnologia, Universidade Estadual Paulista, Presidente Prudente, 2007.

FOUCAULT, M. Arqueologia do saber. Rio de Janeiro: Forense Universitária, 2008.

FREIRE, L. R. da S. C. Saresp 2005: as vicissitudes da avaliação em uma escola da rede estadual. 2008. Dissertação (Mestrado em Educação)-Universidade de São Paulo, São Paulo, 2008.

GOMES, C. A. A educação em novas perspectivas sociológicas. São Paulo: EPU, 2005.

GIRELLI, H. Currículo e cultura: elementos do fracasso escolar. Um estudo com base nas provas do SARESP e FUVEST. 2009. Dissertação (Mestrado em Educação)-Universidade Metodista de São Paulo, São Bernardo do Campo, 2010.

GUTIERRE, M. M. B. Heterogeneidade nas redações escolares: a resposta dos alunos ao SARESP. 2003. Dissertação (Mestrado em Educação)-Universidade Estadual Paulista Júlio de Mesquita Filho, Araraquara, 2003.

HAAS, P. Introduction: Epistemic Communities and International Policy Coordination. International Organization, [S. 1.], v. 46, n.1, p.1-35, 1992.

HERNANDES, E. D. K. Os propósitos e os impactos causados em uma escola da região de Assis pela implantação e pelas mudanças de rumo do SARESP. 2003. Dissertação (Mestrado em Educação)-Universidade Estadual Paulista Júlio Mesquita Filho, Marília, 2003. 
KAWAUCHI, M. SARESP e ensino de História: algumas questões. 2001. Dissertação (Mestrado em Educação)-Faculdade de Educação, Universidade de São Paulo, São Paulo, 2001.

LUGLI, L. de C. A análise de dados e a probabilidade nas avaliações externas para o ensino médio: ENEM e SARESP. 2011. Dissertação (Mestrado Profissionalizante em Educação)-Universidade Cruzeiro do Sul, São Paulo, 2011.

MACHADO, C. Avaliar as escolas estaduais para quê? Uma análise do uso dos resultados do SARESP 2000. 2003. Tese (Doutorado em Educação)-Faculdade de Educação, Universidade de São Paulo, São Paulo, 2003.

MALDONADO, R. G. SARESP e diversidade textual: perspectivas na formação do leitor. 2008. Dissertação (Mestrado em Educação)-Faculdade de Ciências e Tecnologia, Universidade Estadual Paulista Júlio Mesquita Filho, Presidente Prudente, 2008.

MARUCI, F. A de. Leitura e escrita: análise de uma proposta de avaliação por competências e habilidades. 2007. Dissertação (Mestrado em Educação)-Faculdade de Ciências e Tecnologia, Universidade de Sorocaba, Sorocaba, 2007.

MESKO, W. S. Questões de leitura no sistema de avaliação do rendimento escolar do Estado de São Paulo. 2004. Dissertação (Mestrado em Educação)-Faculdade de Educação, Universidade Estadual de Campinas, Campinas, 2004.

NATIS, L. Modelos hierárquicos lineares. Estudos em Avaliação Educacional, [S. 1.], n. 23, p. 3-29, 2011.

OLIVEIRA, D. A. F. de. Uma avaliação política do SARESP. 1998. Dissertação (Mestrado em Educação)-Faculdade de Educação, Universidade Estadual de Campinas, Campinas, 1998.

OLIVEIRA, M. B. de. Formas de autonomia das ciências. Scientiae Studia, São Paulo, v. 9, n. 3, p. 527-61, 2011. 
PINTO, A. R. P. Política pública e avaliação: o SARESP e seus impactos na prática profissional docente. 2011. Dissertação (Mestrado em Serviços Sociais)Faculdade de Ciências Humanas e Sociais, Universidade Estadual Paulista "Júlio Mesquita Filho", Franca, 2011.

PRUDÊNCIO, E. R. Desenvolvimento de vocabulário receptivo, consciência fonológica, leitura e escrita de $1^{a}$ a $4^{a}$ série do ensino fundamental público, e relação com o desempenho na prova de Português do Saresp 2002 (Sistema de Avaliação de Rendimento Escolar do Estado de São Paulo). 2006. Dissertação (Mestrado em Psicologia)-Instituto de Psicologia, Universidade de São Paulo, São Paulo, 2006.

PUENTES, R. V.; AGUINO, O. F.; FAQUIN, J. P. S. Estado del Arte sobre Formación de Profesores en América Latina: significado, orígenes y fundamentos teórico-metodológicos. Revista Digital UMBRAL, [S. 1.], n. 17, 2005.

RAHAL, S. Políticas públicas de Educação: o Saresp no cotidiano escolar. 2010. Dissertação (Mestrado em Educação)-Universidade Cidade de São Paulo, São Paulo, 2010.

RIBEIRO, D. da S. Avaliação do Rendimento Escolar do Estado de São Paulo (SARESP): a educação a serviço do capitalismo. 2008. Dissertação (Mestrado em Educação)-Faculdade de Educação, Universidade Estadual de Campinas, Campinas, 2008.

RIBEIRO, S. J. Analisando o desempenho de alunos do ensino fundamental em Álgebra, com base em dados do SARESP. 2001. Dissertação (Mestrado em Educação)-Pontifícia Universidade Católica de São Paulo, São Paulo, 2001.

RODRIGUES, R. F. Uso e repercussões de resultados do SARESP na opinião de professores da rede estadual paulista. 2011. Dissertação (Mestrado em Educação)- Pontifícia Universidade Católica de São Paulo, São Paulo, 2011.

SÃO PAULO (Estado). Secretaria da Educação. Saresp 2012: Sistema de Avaliação de Rendimento Escolar do Estado de São Paulo. São Paulo, 2012. Disponível em: <http://saresp.fde.sp.gov.br/2012/>. Acesso em: 16 out. 2012. 
SÃO PAULO (Estado). Secretaria da Educação. Programa mestrado \& doutorado. São Paulo, 2012a. Disponível em: <http://www.educacao.sp.gov.br/ portal/projetos/bolsa $>$. Acesso em: 16 maio 2012.

SANDER, B. Consenso e Conflito: perspectivas analíticas na pedagogia e na administração da educação. São Paulo: Pioneira, 1984.

SAZDJIAN, A. B. As redações do SARESP: o texto argumentativo e a análise das três pontas. 2007. Dissertação (Mestrado em Linguística Aplicada e Estudos da Linguagem)-Pontifícia Universidade Católica de São Paulo, São Paulo, 2007.

SERPA, A. L. de O.; PONTES, L. A. F. Bullying escolar e sua percepção pelos alunos: um estudo do Saresp. Estudos em Avaliação Educacional, [S. 1.], v. 24, n. 54, p.118-141, 2013.

SILVA, H. M. G da. Gestão educacional e sistemas de avaliação: os pressupostos ideológicos do SARESP e a trajetória das avaliações aplicadas entre 1996 e 2005. 2006. Dissertação (Mestrado em Educação)-Faculdade de Ciências e Letras, Universidade Estadual Paulista Júlio Mesquita Filho, Araraquara, 2006.

SILVA, J. C. da. Conhecimentos estatísticos e os exames oficiais: SAEB, ENEM e SARESP. 2007. Dissertação (Mestrado Profissionalizante em Educação)Pontifícia Universidade Católica de São Paulo, São Paulo, 2007.

SOARES, M. O Estado da Arte em Alfabetização. Brasília: Inep, 1991.

SOUZA, I. L. de. A competência leitora na perspectiva do SARESP: a habilidade de inferir informação implícita em texto escrito. 2007. Dissertação (Mestrado em Educação)-Pontifícia Universidade Católica de São Paulo, São Paulo, 2007.

TEIXEIRA, M. L. de S. A construção de sentidos na avaliação de múltipla escolha do SARESP. 2005. Dissertação (Mestrado em Estudos Linguísticos)Instituto de Biociências, Letras e Ciências Exatas, Universidade Estadual Paulista Júlio de Mesquita Filho, São José do Rio Preto, 2005. 
TÚBERO, R. O sistema de avaliação de rendimento escolar do Estado de São Paulo e os alunos negros das escolas estaduais da região de Piracicaba. 2003. Dissertação (Mestrado em Educação) - Centro de Educação e Ciências Humanas, Universidade Federal de São Carlos, São Carlos, 2003.

VALLE, R. da C. Teoria da resposta ao item. 1999. Dissertação (Mestrado em Educação)-Instituto de Matemática e Estatística, Universidade de São Paulo, São Paulo, 1999.

VAZ, R. A. da C. SARESP/2005: uma análise de questões de matemática da $7^{\text {a }}$ série do ensino fundamental, sob a ótica dos níveis de mobilização de conhecimentos e dos registros de representação semiótica. 2008. Dissertação (Mestrado Profissionalizante em Educação)-Pontifícia Universidade Católica de São Paulo, São Paulo, 2008.

\section{System of School Performance Evaluation of The State of São Paulo: Thematic Tendencies and Mapping of the Brazilian Scientific Production (1996-2011) \\ Abstract}

This article presents a mapping and analysis of the thematic tendencies of the Brazilian scientific production around the System of School Performance Evaluation of the State of São Paulo (SARESP), regarding the period from 1996 to 2011, systematizing 42 theses and selected dissertations, starting from the following categories: area of expertise, the timeline of the scientific production (chronology), institutional origin, regional distribution, the guiding principles, axes and thematic tendencies. A disposition was verified on the part of the researchers in analyses related to the students' results of the SARESP examinations, concerns for the technical aspects of the constitution of these evaluations and the students' productions, especially in the Portuguese and Mathematics fields, as well as analyses of the impacts of this evaluation format in the school context. It was found a predominance of an epistemic community, hegemonic in the discourse-theoretical terms, and anchored in the paradigm of the conflict.

Keywords: SARESP. Large-scale assessment. Educational assessment. Basic Education. 


\section{Sistema de Evaluación de Rendimiento Escolar del Estado de San Pablo: mapeo y tendencias temáticas de la producción científica brasileña (1996-2011)}

\section{Resumen}

Este artículo presenta un mapeo y análisis de las tendencias temáticas de la producción científica brasileña acerca del Sistema de Evaluación de Rendimiento Escolar del Estado de San Pablo (SARESP), referente al periodo de 1996 a 2011, sistematizando 42 estudios, entre tesis de doctorado y de maestría, a partir de las siguientes categorías: área del conocimiento, línea del tiempo de la producción cientifica (cronología), procedencia institucional, distribución regional, principales tutores y orientaciones, ejes y tendencias temáticas. Se verificó, por parte de los investigadores, una disposición para analizar los resultados de los alumnos en los exámenes de SARESP, preocupaciones con los aspectos técnicos de la constitución de las evaluaciones y las producciones de los alumnos, especialmente en Portugués y Matemáticas, así como análisis de los impactos de ese formato evaluativo en el contexto escolar. Se constató el predominio de una comunidad epistémica, hegemónica en términos teórico-discursivos, basada en el paradigma del conflicto. Palabras clave: SARESP. Evaluación a larga escala. Evaluación Educacional. Educación Básica. 